\title{
Portal Catarinas: estudo de caso de Jornalismo De Novo Tipo
}

\author{
Clarissa do Nascimento Peixoto ${ }^{1}$
}

\begin{abstract}
Resumo:
A partir do conceito de jornalismo de novo tipo, que leva em conta experiências editoriais interessadas em alternativas de produção e circulação de conteúdo jornalístico desvinculadas de grupos hegemônicos, esta pesquisa é um estudo de caso do Portal de Notí cias Catarinas, veículo que atua no jornalismo com perspectiva de gênero e dos direitos humanos das mulheres. Foram utilizados como procedimentos metodológicos a observação participante; entrevistas com editoras, redatoras, colunistas e conselheiras editoriais; análise de conteúdo do blog Somos Muitas - utilizado durante a campanha de crowdfunding do veículo - e do Portal Catarinas. Busca-se refletir sobre potencialidades e limites da experiência, considerando produção de conteúdo; periodicidade; interação com o público e formas de financiamento.
\end{abstract}

\section{Palavras-chave:}

jornalismo de novo tipo; estudo de caso; Portal Catarinas.

\begin{abstract}
:
Based on the concept of journalism of a new type, which takes into account editorial experiences interested in alternative production and circulation of journalistic content unrelated to hegemonic groups, this research is a case study of the Catarinas News Portal, a vehicle which works with gender and women's human rights perspectives. Participant observation; interviews with publishers, writers, columnists and editorial counselors; and content analysis of the Somos Muitas blog - used during the crowdfunding campaign - and the Catarinas Portal were adopted as methodological procedures. A reflection on potentialities and limits of the experience, considering content production and periodicity, interaction with the public and forms of financing are sought in this work.
\end{abstract}

\section{Keywords:}

journalism of a new type; case study; Portal Catarinas.

\footnotetext{
' Mestranda do PPGJor da Universidade Federal de Santa Catarina e pesquisadora do Observatório da Ética Jornalística (ObjETHOS/UFSC). clarissa.jnl@gmail.com
} 


\section{VOZES $_{\text {\&IÁLORO }}^{\mid}$}

Itajaí, v. 18, n. 01, jan/jun 2019

\section{Introdução}

Embora com novos contornos no mundo contemporâneo, a circulação de notícias é uma prática social que remonta à antiguidade. Dos primeiros jornais, passando pela ascensão do capitalismo que transformou as notícias em negócio, até a internet e seus processos não lineares de produção, circulação e interação com o público, o jornalismo se afirma como uma forma de conhecimento da realidade, essencial para a vida coletiva. Ainda que, "reproduza a sociedade em que está inserido com suas desigualdades e contradições" (MEDITSCH, 1997, p.11).

À luz de nosso tempo, é possível observar o quadro de mudanças no modelo de produção e circulação da notícia, marcadamente aquelas verificadas nas últimas décadas do século XX e nas primeiras deste século. A contemporaneidade discute a reconfiguração do jornalismo que, embora mantenha características estruturais do modelo econômico capitalista, passa por transformações em sua dinâmica interna produtiva. Considera-se aqui a mudança de paradigmas, conforme Charron e Bonville (2016, p. 47), que seriam marcas "produzidas e reproduzidas cotidianamente pelos próprios jornalistas e pela prática" que modificam o sistema que rege o fazer jornalístico, agora submetido às novas lógicas sociais, de mercado e tecnológicas, fortemente influenciadas pelas interações promovidas pela sociedade em rede. Micks e Tavares $(2016$, p. 2) também tratam da crise no modelo tradicional do jornalismo, afirmando que "um conjunto complexo de fatores relacionados às transformações no capitalismo contemporâneo afeta dramaticamente o jornalismo, e o polo das receitas das empresas do setor é apenas um dos mais visíveis". Para os autores, há uma crise de governança, que abala as relações de credibilidade.

A mudança de paradigma e a crise de governança no jornalismo se relacionam em transversalidade com o modelo de sistema midiático que, conforme Moraes (2013, p. 20), é formado por megagrupos que detêm a propriedade dos meios de produção, a infraestrutura tecnológica e as bases logísticas, regendo com habilidade o processo de produção material e imaterial. No Brasil, a concentração de mídia atinge o nível de oligopólio o que compromete a pluralidade do pensamento, essencial para as sociedades democráticas. "No setor de comunicação, a existência de diversos grupos competindo não é apenas uma questão de base econômica, mas também política”. É o que aponta Christofoletti (2008, p. 06) quando relembra que a diversidade de grupos não garante somente liberdade sobre preços e produtos, mas assegura a difusão de pontos de vistas múltiplos, o que possibilita o contato com diversas compreensões da realidade. As relações transnacionais no mercado de mídia igualmente incidem sobre o jornalismo. Para Castells (2005, p. 559), “o capital é global ou se torna global para entrar no processo de acumulação da economia em rede eletrônica”. E processos como os de globalização, formação de redes 


\section{VOZES $_{\text {\&IÁLORO }}^{\mid}$}

Itajaí, v. 18, n. 01, jan/jun 2019

e desregulamentação alargam os limites da mídia corporativa e fortalecem oligopólios de redes de negócios multimídia.

É neste contexto em que cresce em ritmo acelerado a precarização do trabalho para profissionais do jornalismo. O Perfil do Jornalista Brasileiro (MICKS e LIMA, 2013, p. 87), demonstra que as transformações estruturais no jornalismo "levam os profissionais a desempenhar novas atividades, criam novas funções e veículos, ajudam a promover a multifuncionalidade e os vínculos precários nas relações de trabalho". As demissões de jornalistas é outra questão enfrentada pela categoria em âmbito nacional. A pesquisa "A conta dos passaralhos", realizada pela agência independente de jornalismo Volt Data Lab e em constante atualização, contabiliza 2.327 demissões de jornalistas em redações desde 2012 e 7.817 demissões totais em empresas de mídia.

Todos esses elementos combinados formam o conjunto de dificuldades para o jornalismo de qualidade. Paralelamente, com a internet, uma possibilidade se abre para outros agentes que procuram disputar espaço na produção e circulação de conteúdo. A internet pode ser vista como uma arena que fomenta o surgimento de experiências editoriais interessadas em produzir outras narrativas jornalísticas, desvinculadas dos grupos hegemônicos, priorizando outras matrizes de fontes de notícias, muitas vezes desconsideradas pelos veículos tidos como tradicionais. A internet também possibilita a atuação profissional de jornalistas que convivem com a precarização do trabalho e a diminuição dos postos de emprego nesses veículos tradicionais.

Considerando os elementos do jornalismo de novo tipo que propõem uma lógica alternativa aos modelos tradicionais de produção e de lucratividade, integrando jornalistas, instituições, leitoras e leitores para a promoção da sustentabilidade do jornalismo, apresenta-se que o Portal Catarinas nesta perspectiva de pensar e fazer jornalístico. Esta pesquisa procura descrever, portanto, a experiência do portal, ao longo do seu primeiro ano de atividade (de março 2016 a março de 2017). O objetivo é refletir sobre potencialidades e limites da experiência, a partir de um estudo de caso, utilizando diversos procedimentos metodológicos como: observação participante; entrevistas semiestruturadas com editoras, redatoras, colunistas e conselheiras editoriais ; análise de conteúdo do blog Somos Muitas e do Portal Catarinas. A partir dos dados coletados, a reflexão sobre potencialidades e limites da experiência considera quatro categorias: produção de conteúdo; periodicidade; interação com o público e formas de financiamento.

\footnotetext{
${ }^{2}$ Entre as 10 mulheres entrevistadas, quatro assumem mais de uma atividade no portal.
} 


\section{VOZES $_{\text {\&DÁLORO }}^{\mid}$}

Itajaí, v. 18, n. 01, jan/jun 2019

\section{O Jornalismo de Novo Tipo}

Originários das transformações nas relações sociais proporcionada pela rede de computadores, os chamados nativos digitais, veículos que nasceram já em linguagem digital, apostam na convergência de formatos sem a necessidade de um aparato sofisticado de produção e distribuição do conteúdo noticioso. Para Harlow e Salaverría (apud HOEWELL, 2018, p. 34), os nativos digitais renovam valores tradicionais do jornalismo, usando técnicas inovadoras para a produção de conteúdos próprios e agregando conteúdos de outros veículos, de colaboradores e da própria audiência. Pesquisa realizada pelo SembraMedia (2017) estudou 100 iniciativas latino-americanas de jornalismo na internet incluindo 25 empreendedores digitais brasileiros. A pesquisa traz alguns dados importantes, como o impacto social do jornalismo produzido por esses nativos digitais, afirmando que transformam a produção e o consumo do jornalismo no continente. Outro aspecto demonstrado pelo estudo é a relação custo/benefício promovida pela internet.

$\mathrm{O}$ advento das mídias sociais e de ferramentas de web design fáceis de usar tornaram possivel lancar um empreendimento de mídia digital quase que inteiramente com patrimônio e esforço próprio. Mais de 70\% dos empreendimen- tos neste estudo comecaram com menos de US $\$ 10$ mil, e mais de $10 \%$ desse total estão gerando pelo menos meio milhão de dólares em receitas anualmente. (SEMBRAMEDIA, 2017).

As formas de financiamento desses veículos são variadas e incluem assinaturas, publicidade e serviços de consultoria. De acordo com a pesquisa, mais de $65 \%$ dos veículos investigados têm múltiplas fontes de receita que vão desde o financiamento coletivo, passando pela promoção de eventos, assinaturas até a veiculação de conteúdo patrocinado. Para a Agência Pública (2017), site jornalístico que empreendeu o "Mapa de Jornalismo Independente no Brasil”, a modalidade de produção e distribuição de conteúdo jornalístico que se constitui na atualidade através da internet é de iniciativas "que nasceram na rede, fruto de projetos coletivos e não ligados a grandes grupos de mídia, políticos, organizações ou empresas".

Segundo Moraes (2009, p. 231), essas dinâmicas editoriais que rejeitam o controle ideológico dos meios tradicionais recorrem ao uso ambivalente da internet. Tais mídias buscam construir uma "ordem social fundada na partilha equânime das riquezas, nos direitos da cidadania e na diversidade cultural”. Ele afirma que esses veículos estão inscritos em um campo comunicacional alternativo, entendido pela acepção construída no Fórum de Medios Alternativos da Argentina, em outubro de 2004, que 


\section{VOZES $_{\text {\&IÁLORO }}^{\mid}$}

Itajaí, v. 18, n. 01, jan/jun 2019

[...] atua como uma ferramenta para a comunicação no campo popular, sem deixar de lado a militância social, ficando implícito que jornalistas e/ou comunicadores devem estar dentro do conflito, sempre com uma clara tendência a democratizar a palavra e a informação (MORAES, 2009, p. 232).

O autor completa destacando que esses meios devem ser independentes do governo, do Estado e das corporações. O caráter alternativo se refere a "um processo comunicacional engajado e participativo que envolve indivíduos e grupos afinados com uma visão politizadora do jornalismo" (MORAES, 2009, p. 232).

Daqueles que se autodenominam como ciberativismo aos que se entendem como jornalismo alternativo, independente ou contra-hegemônico, há no país um conjunto significativo de veículos que produzem e distribuem narrativas dissonantes daquelas construídas pelos meios tradicionais de comunicação. É com base neste contexto que se emprega o termo jornalismo de novo tipo, que sugere uma modalidade do fazer e pensar jornalístico em que a informação é entendida como um direito e não como um produto.

O termo jornalismo de novo tipo, adotado nesta pesquisa, parte do esforço teórico e empírico da equipe de pesquisadores do GPS/Jor, projeto de pesquisa-ação, parceria entre as Universidade Federal de Santa Catarina (UFSC) e Universidade Luterana de Santa Catarina (Ielusc), que tem por objetivo "pesquisar e propor soluções para as crises do jornalismo contemporâneo" (GPS/JOR, 2018). O jornalismo de novo tipo reflete sobre os atuais paradigmas de produção de jornalismo de qualidade, a partir de uma lógica diferenciada do modelo lucrativo, em que os agentes sociais envolvidos - jornalistas, instituições e leitores - integram um conjunto de esforços para a sustentabilidade da atividade jornalística.

Essa lógica é fruto do entendimento de que o cenário comunicacional concentrado e a crise de governança no modelo tradicional de jornalismo, em que a precarização do trabalho é crescente, potencializa a formação de um ambiente para o desenvolvimento de novos arranjos de produção e circulação de conteúdo jornalístico. Esse lugar de encontro não é apenas de interesse dos profissionais de jornalismo, mas de instituições e movimentos sociais que, embora atuem coletivamente na sociedade, seguem à margem da pauta dos noticiários. A perspectiva desta pesquisa-ação é refletir sobre novos paradigmas de produção de jornalismo de qualidade e promover ações que integrem agentes sociais a partir de uma lógica diferenciada do modelo lucrativo, em que a informação é um direito humano.

Conecta-se, portanto, com o conjunto de iniciativas de jornalismo alternativo ou independente e com os movimentos de ativismo comunicacional que se insurgem à lógica dominante. Para Prado (2018, p. 100), um jornalismo "que trabalha lado a lado com os colaboradores, cidadãos e não profissionais, muitas vezes chamado de coletivo e que 


\section{VOZES \\ ¿DIÁl DCo}

Itajaí, v. 18, n. 01, jan/jun 2019

produz farto material, tanto refinado quanto no formato bruto", que se organiza "por microarticuladores e, assim, dissemina seu conteúdo de maneira altamente distribuída no conhecido lema de todos para todos". Essa modalidade de produção jornalística vem crescendo desde as Jornadas de Junho ${ }^{3}$ de 2013, incentivando o nascimento de outros movimentos de comunicação livre, ciberativistas e de contraposição às informações veiculadas pelos tradicionais meios de comunicação.

\section{O Portal Catarinas}

O Portal Catarinas é um veículo de jornalismo multimídia, nativo digital, especializado na temática de gênero, feminismo e direitos das mulheres. É um experiência iniciada em janeiro de 2016 com uma primeira etapa de diálogo entre as idealizadoras do projeto. Foram realizadas várias reuniões para construir os objetivos da proposta e alinhar entendimentos sobre a intersecção entre perspectiva de gênero e jornalismo, diante de um cenário comunicacional bastante concentrado, de produção jornalística hegemonicamente conservadora e estruturalmente machista. Em seguida, se desenvolveram os primeiros rascunhos da linha editorial. Para a segunda etapa, seis mulheres foram convidadas para compor o conselho editorial que ajudou a estruturar a proposta do portal. Em seguida, também foram convidadas mulheres pesquisadoras e ativistas feministas para compor o quadro de colunistas, com o lançamento da plataforma, em julho de 2016. Ao longo do tempo, esse quadro se ampliou e até março de 2017, limite temporal da pesquisa, o Portal Catarinas contava com doze colunistas, além de três editoras e uma jornalista colaboradora. O slogan do Portal, "Jornalismo com perspectiva de gênero", busca acumular a ideia de um jornalismo especializado, com unidade na produção de jornalismo de qualidade e amplitude ao ouvir o conjunto teórico e político do ativismo de mulheres e feministas. Cristiane Mare Silva, colunista do portal destaca que:

A mídia [tradicional] atua na representação de corpos e discursos, não raras vezes tem naturalizado e potencializado as violências vivenciadas pelas mulheres. Portanto, um jornalismo que rompa com essas estruturas e que seja capaz de dialogar com gênero/raça/classe e orientação sexual, assume um projeto político de emancipação da nossa sociedade, sem a pretensa e falsa ideia de um jornalismo neutro, imparcial e distante. Nosso jornalismo diz que somos protagonistas de nossas histórias, que é possível fazer fissuras nestes discursos hegemônicos e acolhermos umas as outras. (ENTREVISTA À AUTORA, 2017).

${ }^{3}$ Protestos que ocorreram nas ruas de diversas cidades brasileiras em junho de 2013, desencadeadas pelo Movimento Passe Livre, contra o aumento das tarifas do transporte público em São Paulo. 


\title{
VOZES $_{\text {\&IÁLORO }}^{\mid}$
}

Itajaí, v. 18, n. 01, jan/jun 2019

O ativismo feminista foi um elemento essencial para a elaboração da linha editorial de Catarinas. A partir de uma perspectiva ampla, de encontro entre as diversas vertentes do feminismo, buscou-se produzir jornalismo com perspectiva de gênero, em que a narrativa é constituída a partir da interseccionalidade entre classe, raça, gênero, onde se busca a pluralidade de fontes, que na sua larga maioria são mulheres; a perspectiva antimachista e antirracista; e a construção do texto a partir de um nova lógica, marcadamente feminina. Por isso, define-se como um veículo de comunicação especializado, por investir em um conteúdo segmentado, mas que busca aprofundamento. De qualquer forma, não é só a pauta que traz a marca de gênero. Busca-se, no exercício cotidiano, tratar das questões de gênero indiretamente, através da produção iminentemente feminina, feita exclusivamente por feministas, incluindo as atividades de edição e planejamento.

\begin{abstract}
A linha editorial de Catarinas se encontra na intersecção entre o jornalismo como um direito e os direitos humanos como uma premissa básica para a produção do jornalismo. Também se identifica como feminista, pretendendo o diálogo com as diversas linhas teóricas e políticas do feminismo, mediando suas perspectivas diante da realidade. Dentro da compreensão ética do exercício profissional do jornalismo, Catarinas se coloca com uma unidade ativista do jornalismo enquanto direito e do feminismo enquanto estratégia de ação para a superação desta sociedade que ainda reserva lugares para as mulheres”. (PORTAL CATARINAS, 2017).
\end{abstract}

A proposta inicial considerava três objetivos: realizar curadoria de informação sobre as temáticas gênero, feminismo e direitos das mulheres; a observação dos debates públicos sobre estes temas, notadamente apresentados pela mídia tradicional; e a produção de conteúdo próprio. Antes mesmo do lançamento do portal, esse trabalho passou a ser desenvolvido. A curadoria é o exercício com menos entraves e que mantém a periodicidade diária na página do portal no Facebook. No Portal, a curadoria segue de forma mais sazonal, pois é priorizada a publicação de conteúdo próprio, assim como em outras redes sociais como o Instagram e o Twitter. A observação dos debates públicos que se relacionam com as questões de gênero acontece de forma esporádica, de acordo com a demanda que chega através de leitoras e leitores ou mesmo da observação diária, parte do trabalho de curadoria. A produção de conteúdo, que completa o tripé de trabalho do Portal, é a que mais gera mobilização e atenção das responsáveis pelo Catarinas e é a que encontra maior dificuldade para a realização por demandar recursos humanos e financeiros, ainda escassos nesta primeira etapa de vida deste veículo de informação..

A campanha de financiamento coletivo foi um elemento importante para a estruturação do Portal Catarinas. O processo, para além de subsidiar a plataforma, arcando com os custos de trabalho de uma designer e uma programadora, possibilitou a mobilização em torno do projeto e o engajamento de uma série de agentes, interessados em novas perspectivas para o jornalismo, sobretudo na esfera local, e no debate político sobre direitos 


\title{
VOZES $_{\text {\&IÁLORO }}^{\mid}$
}

Itajaí, v. 18, n. 01, jan/jun 2019

humanos, com ênfase nas mulheres. Neste processo, algumas ferramentas foram essenciais, como o uso da rede social Facebook e do blog Somos Muitas, que abrigou a produção de conteúdo da fase anterior ao lançamento do Portal. Ao atingir a meta estabelecida pela plataforma de financiamento, em abril de 2016, foi iniciado o trabalho de construção do Portal, lançado na Fundação Cultural Badesc, no dia 28 de julho de 20164.

A produção de conteúdo do Portal está ligada a um processo de trabalho coletivo, iniciado nas reuniões de pauta que acontecem, em geral, uma vez por semana. Muitas vezes esse processo ocorre via internet, em chats de conversa. Lá se definem as pautas por ordem de prioridade e de possibilidade para a produção, levando em consideração que ainda não se consegue ter jornalistas focadas apenas no Portal. O trabalho conta com o voluntariado das profissionais que também despendem seus equipamentos para a consecução das atividades. O processo de trabalho de uma ação coletiva, na maioria dos casos, do começo ao fim do processo produtivo de uma pauta, desenvolvida por mais de uma pessoa, embora de forma linear (reunião de pauta, pesquisa e entrevistas, checagem, redação e edição). Divididas as tarefas, as dificuldades ficam por conta da infraestrutura para subsidiar deslocamentos, ligações e outras condições necessárias para a realização da pauta. O valores arrecadados pela forma de financiamento desenvolvida pelo veículo até o período da pesquisa ainda não davam conta de remunerar profissionais para o trabalho e garantir toda a estrutura necessária para a produção, como destaca uma das colunistas, Cristiane Brasileiro:

\begin{abstract}
Catarinas tem sobrevivido com recursos econômicos incrivelmente modestos, quando penso no volume na qualidade altíssima do trabalho jornalístico [...] acho que as editoras conseguiram um feito realmente extraordinário [...] $\mathrm{O}$ Portal não só filtra e reúne notícias que dizem respeito ao assunto diante de todo o seu público, mas também apresenta produção própria de alta qualidade, com reportagens especiais e editoriais que têm uma densidade muito acima da média dos jornais do país. Nesse sentido, o Portal não só aumenta e concentra o nosso acesso a muita informação e reflexão, mas também fortalece e amadurece uma perspectiva diferenciada a respeito das mesmas notícias que por vezes até se poderia ver noutros veículos. E o que é muito importante: mostra, na prática, que isso é possível! (ENTREVISTA À AUTORA, 2017).
\end{abstract}

A partir dos entraves na produção de conteúdo, é possível aferir como limites da experiência a dificuldade em manter a periodicidade, fator essencial para o relacionamento com o público, segundo as entrevistadas. Ana Claudia Araújo, uma das editoras, afirma que a periodicidade pretendida é a diária, porém, relata que nem sempre conseguem mantê-la com esta frequência, por conta da "morosidade na produção de algumas pautas, considerando o tempo escasso e a falta de dedicação exclusiva para a produção", reflexo da realidade em que as produtoras de conteúdo precisam exercer outras atividades remuneratórias e também se dedicam a tarefas administrativas e institucionais do Portal.

\footnotetext{
4 Mais de 160 pessoas apoiaram o projeto na plataforma Catarse e tantas outras contribuíram com sua arte, trabalho e mobilização em rede. A arrecadação de $\mathrm{R} \$ 16.985$ gerou renda direta e indiretamente para cerca de 20 pessoas (PORTAL CATARINAS, 2018).
} 


\section{VOZES $_{\text {\&IÁLORO }}^{\mid}$}

Itajaí, v. 18, n. 01, jan/jun 2019

O conteúdo do Portal é atualizado de duas a três vezes por semana, pois a falta de estrutura mínima para manter o coletivo de jornalistas não está em consonância com o aprofundamento que se busca na pauta, com a diversificação de fontes, por exemplo, além do trabalho de edição mais detalhado que esta atividade requer. A ação diária mantida é o de curadoria de informação, como já foi relatado, através de uma rede social específica, e as demais são atualizadas na medida em que conteúdo próprio é produzido. Todas as entrevistadas defendem que os números de audiência e de assinantes poderiam melhorar caso a periodicidade fosse menos volátil. Embora não haja um estudo mais aprofundado por parte do Portal sobre o retorno do público neste quesito, as entrevistadas sugerem que o aumento da produção de conteúdo e, portanto, a manutenção da periodicidade diária do portal, são fatores essenciais para ampliar o público e motivá-lo ao diálogo com o veículo. Segundo as entrevistadas, a experiência demonstra que o conteúdo próprio gera mobilização no Portal e nas redes sociais, ampliando o raio de audiência do veículo. Paula Guimarães, uma das editoras, credita a falta de produção diária de conteúdo próprio “de notícias ou materiais mais aprofundados (não factuais)" como entrave para que o veículo atraia leitoras e leitores em busca de conteúdos diários.

A relação com o público também esbarra na questão estrutural. Tendo em vista que a experiência demonstra que a ampliação de audiência está relacionada à produção de conteúdo próprio, as entrevistadas afirmam que a viabilidade financeira novamente aparece como entrave para a melhora de números desse medidor. A página no Facebook conta com mais de 17 mil assinantes e gera um alcance semanal nas publicações de mais de 100 mil visualizações. No portal, o acesso cresce com a publicação de conteúdo próprio e tem picos de acesso ainda pouco regulares, ora com textos de colunistas que já contam com um público externo, ora com matérias factuais polêmicas ou com reportagens mais aprofundadas. A avaliação das entrevistas demonstra que se atingiu apenas um primeiro raio de público e que é necessário ampliar a audiência. Ana Claudia Araujo acredita que "a concorrência, na temática e na proposta, com veículos do centro do país e a cultura local ainda muito viciada nos veículos tradicionais" são aspectos dificultados para a melhora nos números da audiência. Como alternativa, a jornalista julga ser essencial promover "o portal junto aos públicos de interesse da pauta, realizando pesquisa com leitoras e leitores para aferir as pautas que tem maior aceitação/interação". É importante dizer que as ferramentas para o diálogo com o público ainda se restringem aos chats das redes sociais e a troca de emails, porém, pela proximidade das próprias jornalistas com leitoras e leitores, há um retorno pessoal para cada uma, em e-mails particulares ou pessoalmente.

Sobre a produção de conteúdo, a periodicidade e audiência do Portal, a jornalista e colaboradora do Catarinas Daiana Constantino afirma: 


\section{VOZES $_{\text {\&IÁLOGO }}^{\mid}$}

Itajaí, v. 18, n. 01, jan/jun 2019

Sei bem que fazer jornalismo alternativo às mídias tradicionais não tem retorno financeiro suficiente (pelo menos por enquanto) para manter uma estrutura ideal para fazer grandes coberturas e reportagens. Então, vou fazer uma avaliação pé no chão. Acho que o Portal encontrou uma saída interessante para se manter em evidência nas redes sociais, compartilhando reportagens e textos de outros veículos, coletivos, etc., com assuntos que tenham a ver com a proposta editorial de Catarinas. Apesar das dificuldades financeiras, vejo que o Portal está atento à pauta da Capital/nacional para acompanhar assuntos mais factuais, e toda semana apresenta entrevistas e matérias de serviço, com eventos e especialistas. (ENTREVISTA À AUTORA, 2017).

A sustentabilidade econômica é a maior dificuldade encontrada na experiência de Catarinas. Por um lado, a aposta em uma perspectiva de jornalismo que se desloca da ideia de lucratividade e tem a informação como um direito é um desafio premente; por outro, se concentram os impasses de estabelecer formas de custeio da atividade. O Portal Catarinas apostou em um primeiro momento no modelo de crowdfunding para levantar recursos para o lançamento da plataforma. A experiência foi exitosa, mas também revelou os seus limites. Embora seja uma ferramenta de mobilização e visibilidade, a campanha de financiamento coletivo requer muito esforço e não se apresenta como uma alternativa viável para a manutenção a longo prazo de um projeto jornalístico se não for casada com outras formas de sustentabilidade. Para diversificar a arrecadação de recursos do projeto, a equipe do Portal também lançou uma plataforma de contribuição, através de doações e assinaturas. O resultado ainda é insuficiente e isso se dá pela falta de pessoal que possa pensar, paralelamente ao trabalho editorial desenvolvido, em uma campanha que mobilize leitoras e leitores a apoiar a produção de conteúdo. O Portal ainda mantém o Leilão Catarinas, uma tática utilizada na campanha de financiamento coletivo - e que naquele momento teve maior funcionalidade - em que obras de arte doadas por artistas engajadas/os na proposta são vendidas através do Portal. Nesta etapa, o leilão perdeu força e não tem gerado retorno financeiro.

Neste contexto, a equipe de Catarinas se debruça em outras possibilidades. A primeira relacionada à ideia de publicidade. Ainda não há um entendimento claro sobre como operar neste sentido. O projeto gráfico do site já suporta espaços publicitários, mas a dificuldade fica por conta da falta de pessoal especializado neste trabalho e que ainda não foi possível agregar ao veículo. Outra possibilidade é a venda de produtos pelo próprio Portal, como camisetas, sacolas, bótons, etc., tal qual se faz a venda de obras de arte no leilão Catarinas. Esse formato encontra obstáculos, principalmente o subsídio financeiro para produzir o material. A colunista e apoiadora do Portal, Cristiane Brasileiro, aponta limites:

Dos pontos mais frágeis, eu destacaria o lugar meio obscuro e o caminho meio labiríntico enfrentado por quem tivesse interesse em apoiar financeiramente o trabalho. Acho que essa oportunidade deveria 


\section{VOZES $_{\text {\&IÁLORO }}^{\mid}$}

Itajaí, v. 18, n. 01, jan/jun 2019

aparecer com muito mais frequência aos leitores, assim com as eventuais vantagens de se ter uma assinatura do Portal. (ENTREVISTA À AUTORA, 2017).

Para dar suporte ao Portal, e dar conta de uma demanda de mobilização social gerada pelo veículo que, em larga medida se coloca em um horizonte ativista, optou-se pela criação da Associação Catarinas. O objetivo é viabilizar a manutenção do veículo e organizar o sistema de gestão de pessoal e recursos, obedecendo a horizontalidade na tomada de decisões e a verticalidade na execução de ações, subdividida em três diretorias e um conselho. A organização surge como um guarda-chuva com a intenção de ser a mantenedora do Portal e realizar outras atividades que lhe dêem suporte. A partir da Associação, o Portal Catarinas busca participar de uma série de editais e propostas de financiamento em âmbito nacional e internacional que possibilitem a realização tanto de projetos no campo da comunicação e do jornalismo, quanto no feminismo. A equipe tem se dedicado em estudar e escrever projetos, mas ainda não garantiu resultados mais concretos, frente ao contexto apresentado e uma realidade cada vez mais adversa aos movimentos sociais em geral.

Com este estudo de caso buscou-se relacionar o objeto de estudo escolhido, o Portal Catarinas, com a perspectiva do Jornalismo de Novo Tipo, empregada como referencial teórico desta pesquisa. Considera-se para traçar essa relação, a perspectiva das jornalistas que idealizaram o projeto, consonante aos pressuposto que fomentariam o aparecimento de novos modelos de produção e gestão de veículos jornalísticos, de acordo com as formulações sobre o Jornalismo de Novo Tipo, como o cenário comunicacional concentrado e a crise de governança no modelo tradicional de jornalismo, com a crescente precarização do trabalho. O Portal Catarinas também tem como objetivos produzir jornalismo de qualidade e promover ações que integrem agentes sociais interessados em atuar no jornalismo a partir de uma lógica diferenciada do modelo lucrativo, em que a informação é considerada como um direito e não uma mercadoria. Esses princípios traçam paralelo à ideia empregada no conceito de Jornalismo de Novo Tipo, sobretudo, porque o Portal Catarinas tem como foco o direito humano das mulheres. Além disso, o Portal se soma ao conjunto de iniciativas que busca promover o jornalismo de forma alternativa aos veículos tradicionais de comunicação e que atuam de forma independente de grandes grupos políticos e econômicos.

\section{Considerações}

Catarinas começou com o objetivo de realizar curadoria de informação, produzir conteúdo, observar a mídia sobre assuntos relacionado aos debates de gênero, direito das mulheres e feminismo. Na primeira etapa de trabalho, observada por essa pesquisa, o 


\section{VOZES $_{\text {\&IÁLORO }}^{\mid}$}

Itajaí, v. 18, n. 01, jan/jun 2019

Portal conseguiu manter a proposta, com ênfase na curadoria de informação diária, com a produção de conteúdo semanal e eventualmente funcionando como observatório. A experiência de Catarinas mostra que havia uma lacuna importante neste espaço em que o jornalismo com perspectiva de gênero se inscreve. A especialidade foi bem recebida pelo público, carente de um diálogo sobre direitos humanos das mulheres e feminismos, embora ainda estejamos falando de um conjunto pequeno de pessoas e muito próximo ao cotidiano do Portal. Neste sentido, a relação com o público se dá de forma bastante localizada através de um diálogo ainda insuficiente via redes sociais. No entanto, a perspectiva é apostar no estreitar de laços, fortalecendo essa relação. Um exemplo desse esforço foi a reunião de pauta aberta, realizada em março de 2017, numa tentativa de ouvir o público, trocar experiências e aproximar as pautas do Catarinas da expectativa de quem o acompanha. Para as entrevistadas, o Portal tem vocação para criar laços entre leitoras e leitores, e fortalece uma espécie de comunidade de aprendizagem e de discussão permanente junto a uma parte da população que, via de regra, tem mesmo mais limitações e dificuldades para participar da vida pública se pronunciando, ouvindo e sendo ouvida.

O que se evidencia como desafio a ser superado é a manutenção da produção de conteúdo próprio com uma periodicidade melhor definida, para ampliar audiência, mas a falta de recursos afeta esta produção de conteúdo que irrompe com a consequência de uma periodicidade mais constante. Esse fator também desmobiliza o público. O problema que requer solução é o desenvolvimento de um modelo de financiamento sustentável que não parece vir de um só lugar e sim de uma diversidade de formas de sustentabilidade econômica.

Um elemento ainda controverso é a regionalidade da experiência. Por um lado, sente-se a tensão para nacionalizar a pauta, as fontes e a própria mão-de-obra (colunistas e jornalistas que estejam em outros lugares) - para atingir novos públicos; por outro, é fundamental destacar que o fato de ser um projeto fora do eixo político e econômico com ênfase na região Sudeste, faz da proposta algo mais ousado e desalinhado com o mainstream ou mesmo com a lógica da narrativa jornalística hegemônica.

Nesta primeira fase, o Catarinas se posicionou como um veículo alternativo à lógica hegemônica e independente de grupos políticos e econômicos. No entanto, a iniciativa também demonstra limites. Para garantir um jornalismo de qualidade, é necessário buscar condições de financiamento e gestão que garantam a estrutura para a produção, retendo e ampliando a audiência. A falta de recursos impacta severamente a qualidade do conteúdo produzido, gerando um desgaste laboral das profissionais envolvidas que, de forma voluntária, se desdobram nas multifunções. No que se refere ao público, a pesquisa demonstrou que, embora ainda estivesse em uma primeira etapa, a audiência segue crescente. No entanto, a dificuldade está em criar ferramentas de mais interação, resultante da falta de profissionais e recursos para construir esse diálogo imprescindível para quem 


\section{VOZES $_{\text {\&DÁLORO }}^{\mid}$}

Itajaí, v. 18, n. 01, jan/jun 2019

produz conteúdo jornalístico nos meios digitais. Essa carência de recursos também inviabiliza uma periodicidade mais dinâmica, o que acarreta em desmobilização do público.

Por fim, destaca-se que a experiência de Catarinas demonstra que o caminho para consolidar e manter iniciativas como essa passa por agregar diferenciadas formas de sustentabilidade econômica e, fundamentalmente, por um trabalho de diálogo com o público em que se defenda a ideia da informação como um direito e o jornalismo, portanto, como uma ação de interesse social e não de mercado.

\section{Referências}

AGÊNCIA PÚBLICA. O mapeamento do jornalismo independente. Disponível em <goo.gl/t3ajve>. Acesso em: 13 mar. 2017.

. O que descobrimos com o mapa do jornalismo independente. Disponível em 〈goo.gl/MHS2aJ〉. Acesso em: 13 mar. 2017.

ARAUJO, Ana Claudia. Entrevista [jan. 2017]. Entrevistadora: Clarissa Peixoto.

BLOG SOMOS MUITAS. Disponível em: 〈https://bit.ly/2DzolcX> Acesso em: 13. jan. 2017.

BRASILEIRO, Cristiane. Entrevista [jan. 2017]. Entrevistadora: Clarissa Peixoto.

CASTELLS, Manuel. A sociedade em rede. 8 ed. São Paulo: Paz e Terra, 2005.

CHARRON, Jean; Bonville, Jean de. Natureza e transformação do jornalismo. Florianópolis/Brasília: Insular, 2016.

CHRISTOFOLETTI, Rogério. Concentração de mídia, padronização jornalística e qualidade do noticiário: o caso de Santa catarina. Anais do VI Encontro Nacional de Pesquisadores em Jornalismo. Associação Brasileira de Pesquisadores em Jornalismo. São Paulo: UMESP, novembro de 2008.

CONSTANTINO, Daiana. Entrevista [jan. 2017]. Entrevistadora: Clarissa Peixoto.

DUARTE, Marcia Yukiko Marsuuchi. Estudo de caso. In DUARTE, Jorge; BARROS, Antônio (Orgs.). Métodos e técnicas de pesquisa em comunicação. São Paulo: Atlas, 2005. p. 215-235.

GPS/JOR. Disponível em 〈https://bit.ly/2QZI9J8>. Acesso em: 17.set.2018.

GUIMARÃES, Paula. Entrevista [jan. 2017]. Entrevistadora: Clarissa Peixoto.

HOEWELL, Gabriel Rizzo. A configuração da informação jornalística no contexto da convergência: uma análise do Nexo. Porto Alegre: Universidade Federal do Rio Grande do Sul, 2018. 186 p. Dissertação de Mestrado, Programa de Pós-graduação em Comunicação e Informação. 


\section{VOZES

 \\ Itajaí, v. 18, n. 01, jan/jun 2019}

LIMA, Samuel Pantoja. Governança social, produção e sustentabilidade para um jornalismo de novo tipo. Disponível em <goo.gl/96gEWM>. Acesso em: 17 mar. 2017. ; MICK, Jacques. Perfil do Jornalista Brasileiro: características demográficas, políticas e do trabalho jornalístico em 2012. Florianópolis: Insular, 2013.

MEDITSCH, Eduardo. O jornalismo é uma forma de conhecimento? CONFERÊNCIA NOS CURSOS DA ARRÁBIDA. Universidade de Verão. Set. 1997.

MICK, Jacques; TAVARES, Luisa. A crise de governança do jornalismo contemporâneo. ENCONTRO REGIONAL DE JORNALISMO ONLINE, 3. Porto Alegre, Unisinos, 17 out. 2015.

MORAES, Dênis;. A batalha da mídia: governos progressistas e políticas de comunicação na América Latina e outros ensaios. Rio de Janeiro: Pão e Rosas: 2009. ; RAMONET, Ignacio; SERRANO, Pascual. Mídia, poder e contrapoder: da concentração monopólio à democratização da informação. FAPERJ/Boitempo Editorial. 2013.

PORTAL CATARINAS, 2017. Linha editorial. Disponível em: 〈https://bit.ly/2zvlixf> Acesso em: 13. jan. 2017. , 2018. A campanha. Disponível em: 〈https://bit.ly/2OSqZM4> Acesso em: 25. set. 2018.

PRADO, Magaly. Ciberativismo e noticiário: da mídia torpedista às redes sociais. Rio de Janeiro: Alta Books, 2015.

SEMBRAMEDIA. Ponto de inflexão: impacto, ameaças e sustentabilidade: um estudo dos empreendedores digitais latino-americanos. 2017. Disponível em:

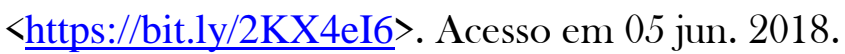

SILVA, Cristiane Mare. Entrevista [jan. 2017]. Entrevistadora: Clarissa Peixoto.

VOLT DATA LAB. A conta dos passaralhos: um panorama sobre demissões de jornalistas nas redações do Brasil de 2012. Disponível em: 〈https://bit.ly/2xNh3NJ> Acesso em: 25 jan. 2017. 